\title{
Cost-Minimisation Analysis of Erythropoiesis-Stimulating Agents in the Treatment of Anaemia in Dialysed Patients: A Pilot Study
}

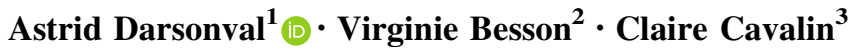

Published online: 9 March 2017

(c) The Author(s) 2017. This article is published with open access at Springerlink.com

\begin{abstract}
Objective This study aimed to assess the cost impact of administering erythropoiesis-stimulating agents once every 4 weeks instead of one to three times a week to treat anaemia in patients undergoing dialysis.

Methods This was a monocentric retrospective study involving 27 patients who underwent haemodialysis between 2009 and 2013 in a university hospital in Angers, France. The study was a cost-minimisation analysis from the hospital perspective. Only direct medical costs were considered.

Results This study demonstrated that therapeutic management of anaemia with methoxy polyethylene glycol-epoetin beta would save medical and nurse time ( 7 days and 15 days per year, respectively) and reduce costs by $€ 59,960$ a year for an active file of 40 patients undergoing haemodialysis, assuming a $100 \%$ occupancy rate in the above-mentioned hospital.

Conclusion This study indicated that treating anaemia by administering erythropoiesis-stimulating agents once every 4 weeks instead of one to three times a week in patients undergoing haemodialysis would be beneficial for the hospital.
\end{abstract}

Astrid Darsonval

asdarsonval@chu-angers.fr

1 Service Pharmacie, Centre Hospitalier Universitaire, 49100 Angers, France

2 Service Hémodialyse, Centre Hospitalier Universitaire, 49100 Angers, France

3 Cellule d'évaluation médico économique, GIRCI Grand Ouest, Tours, France

\section{Key Points for Decision Makers}

This study aimed to assess the cost impact of implementing a new therapeutic strategy for treating anaemia in patients undergoing dialysis.

Treating anaemia with methoxy polyethylene glycolepoetin beta in patients undergoing haemodialysis may reduce costs related to the management of these patients in a hospital environment.

\section{Introduction}

The incidence of chronic kidney failure continues to increase in developed countries. This condition gradually progresses to end-stage chronic kidney failure, which requires replacement therapy-extra-renal purification or kidney transplant. This sustained increase in prevalence means that chronic kidney failure has become a significant public health concern in many countries, including France. According to the French National Authority for Health (Haute Autorité de Santé [HAS]) guidance note, Medical and Economical Assessment of Kidney Failure Management Strategies in France (September 2010), the prevalence of chronic kidney failure in France is one of the highest after the USA and Germany. French Renal Epidemiology and Information Network data from 31 December 2013 [1] estimated that 76,187 people were undergoing replacement therapy by dialysis or kidney transplant (i.e. 1163 people treated per 1 million inhabitants), $44 \%$ of whom were living with functional kidney grafts and $56 \%$ of whom were undergoing dialysis. 
One of the consequences of chronic kidney failure is anaemia caused by insufficient synthesis of erythropoiesis. It can cause systolic dysfunction and heart failure [2-4], and treating it in patients with chronic kidney failure increases the survival rate, reduces morbidity and improves quality of life.

In June 2013 [5], HAS published best practice guidelines for treating chronic kidney failure-related anaemia in order to slow the progression of heart complications and improve patients' quality of life. According to a recent HAS report [6], best practice guidelines set a target haemoglobin concentration of between 9 and $13 \mathrm{~g} / \mathrm{dl}$ in patients undergoing haemodialysis being treated with an erythropoiesis-stimulating agent (ESA).

In 2007, a new ESA with a long half-life and a dosing schedule of one injection every 4 weeks reached the market. Therefore, an assessment of the cost impact of implementing a new type of management was justified.

Given the frequency of the disease and the cost of purchasing ESAs, treating anaemia in patients with chronic kidney failure is a major economic challenge. Evaluating the factors that define the medical costs related to ESAs can support decision making in the selection of the most efficient ESA for treating anaemia in patients with chronic kidney failure.

A literature review [7-9] indicated that administering methoxy polyethylene glycol (MPG)-epoetin beta once a month reduced costs and saved time; however, the results were not unanimous and key criteria were heterogeneous, making comparison difficult.

The Tempo [10] study assessed the amount of time that would be saved by switching from several injections a week (or twice a month) to one monthly injection. The results of this French study indicated that switching to one monthly injection would save up to 32.5 days of work per patient and per year for pharmacists/pharmacy technicians and nurses.

The results of these various works, combined with the current context of budget cuts and the search for efficiency, confirm the relevance of our study.

The objective of this study was to demonstrate whether treating anaemia with MPG-epoetin beta in patients undergoing dialysis reduced costs related to the management of these patients in a hospital environment. If so, this could translate into cost savings because of the time saved, mainly for nurses, which could in turn lead to a reorganisation of the haemodialysis service.

\section{Methods}

\subsection{Design of the Study}

Several studies [11, 12] have demonstrated that the efficiency and tolerance of MPG-epoetin beta is equal to that of erythropoietins. Furthermore, on 19 December 2007, the French Transparency Committee [13] concluded that "MPG-epoetin beta has been as efficient as the other erythropoiesis-stimulating agents and has a similar tolerance profile," confirming these results. Therefore, we chose to evaluate this new type of management using a cost-minimisation analysis.

A cost-utility analysis may have been possible. However, our study compared two therapeutic strategies (administration three times a week vs. once every 4 weeks) that have no direct impact on patients' quality of life. Indeed, patients are unaware of ESA administration because it occurs directly at the dialysis generator; neither the number of dialyses nor the general care of the patient changes. However, the literature review [2-5] did show that treating anaemia slows the progression of heart complications and reduces morbidity, thereby improving patient quality of life. Furthermore, the retrospective nature of our study meant we could not ask patients to complete a quality-of-life questionnaire, particularly as some of the patients had died.

This is a retrospective monocentric comparative 'before/ after' study in which patients acted as their own control. We calculated only direct medical costs as defined in the traditional terminology of economic evaluation described in the French College of Health Economists methodological guide for the economic assessment of health strategies [14]. The study was conducted from the hospital's perspective and compared two methods of managing anaemia: administration of ESA one to three times a week (erythropoietin alpha or beta) versus every 4 weeks (MPGepoetin beta).

Our hypothesis was that the implementation of a new administration method for treating anaemia in patients undergoing dialysis could reduce management costs in a French hospital environment.

\subsection{Study Population}

The population included patients aged $>18$ years undergoing haemodialysis who had anaemia that had been treated with an ESA one to three times a week over a 6-month period and a pegylated ESA once every 4 weeks over a subsequent 6-month period. This study enabled the comparison of two populations of patients (Fig. 1). Conversion from erythropoietin alpha or beta to MPG-epoetin

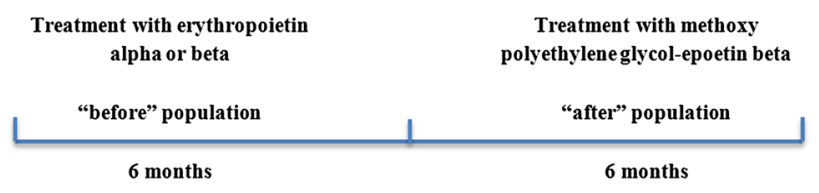

Fig. 1 Schema of the two periods of study 
beta complied with the summary of product characteristics recommendations: The initial dose of MPG-epoetin beta was calculated based on the weekly dose of erythropoietin alpha or beta previously administered at the time of the substitution, and the first injection began on the date planned in the previous administration schedule for the erythropoietin alpha or beta.

Each patient acted as their own control. There were two types of measured parameters: fixed variables, measured once when the patient entered the study, and time-related variables, measured every month during the study. Data collection was retrospective over the period between 2009 and 2013.

\subsection{Cost-Minimisation Analysis}

The cost-minimisation analysis was carried out from the hospital perspective. Data were collected via follow-up of the cohort of patients undergoing haemodialysis who were treated with an ESA or a pegylated ESA between 2009 and 2013. The year of valuation corresponded to the year of ESA administration (2009-2013). Costs were calculated from negotiated real prices adjusted year to year. Unit cost values are detailed in Table 1. The evaluation was conducted over a 12-month period and assessed the direct medical costs (Table 2) related to resources that were likely to vary between the two therapeutic strategies over the time horizon. The costs were estimated according to a sophisticated approach to the real costs (micro-costing) and are expressed in $€$.

The average medical time per prescription of ESA represents the exclusive time for prescription with regard to the results of the biological balance sheet and was obtained from real-world timing. The physician was the same person (a single physician) in both before and after groups.

We conducted a univariate deterministic sensitivity analysis (tornado diagram) using three relevant variables:

- time for ESA prescription per practitioner,

- time for ESA administration per nurse,

- cost of acquiring ESA.

Medical time includes the time from receiving the biological results and entering the data into the system until the prescription of ESAs. Nursing care time includes the time spent administering the ESAs, including removing the ESA from the refrigerator, disinfecting the injection area, preliminary control of the ESA according to the patient and the prescription (verifying concordance between patient identity and the dose prescribed for this patient before administering the ESA), administering the ESA (injection) and logging the administration (electronic traceability).

\section{Results}

\subsection{Statistical Analysis of the Population}

A total of 27 patients who underwent haemodialysis between 2009 and 2013 were eligible for this study (Fig. 2); 62\% were men, and the average age was $70.3 \pm 11.5$ years. Diabetes $(37.9 \%)$ and hypertension $(58.6 \%)$ were the main cardiovascular risk factors. All patients were monitored in the haemodialysis service. The average ratio $\mathrm{spKt} / \mathrm{V}$ (used to measure haemodialysis adequacy) was $1.6 \pm 0.3$.
Table 1 Description of the unit cost values

\begin{tabular}{ll}
\hline Variable & Unit cost values $(€)$ \\
\hline Average hourly pay for hospital physician: 2010 & 42 \\
Hourly pay for nurse: 2010 & 25 \\
ESAs one to three times per week (varies according to year) & $0.0035-0.0074$ per IU \\
ESAs every 4 weeks (varies according to year) & $1.4294-1.6234$ per $\mu \mathrm{g}$ \\
Iron (varies according to year) & $6.1260-13.2526$ per vial \\
\hline
\end{tabular}

ESA erythropoiesis-stimulating agent

Table 2 Description of the direct medical costs and method of their calculation

\begin{tabular}{ll}
\hline Cost description & Method of calculating the costs \\
\hline Medical time for the prescription of ESAs & Average medical time per ESA prescription $\times$ number of prescriptions \\
Nursing care time for the administration of ESAs & Average nursing care time per ESA administration $\times$ number of administrations \\
Acquiring ESAs & Price, including all taxes, per unit $\times$ number of units administered \\
Acquiring injectable iron & Price, including all taxes, per unit $\times$ number of units administered \\
Administering ESAs (technical medical procedures) & Number of procedures for ESA administration $\times$ two AMI \\
Administering injectable iron (technical medical procedures) & Number of procedures for injectable iron administration $\times 2$ AMI
\end{tabular}

AMI Acte Médico Infirmier (nursing procedure), ESA erythropoiesis-stimulating agent 
Fig. 2 Cohort of eligible patients

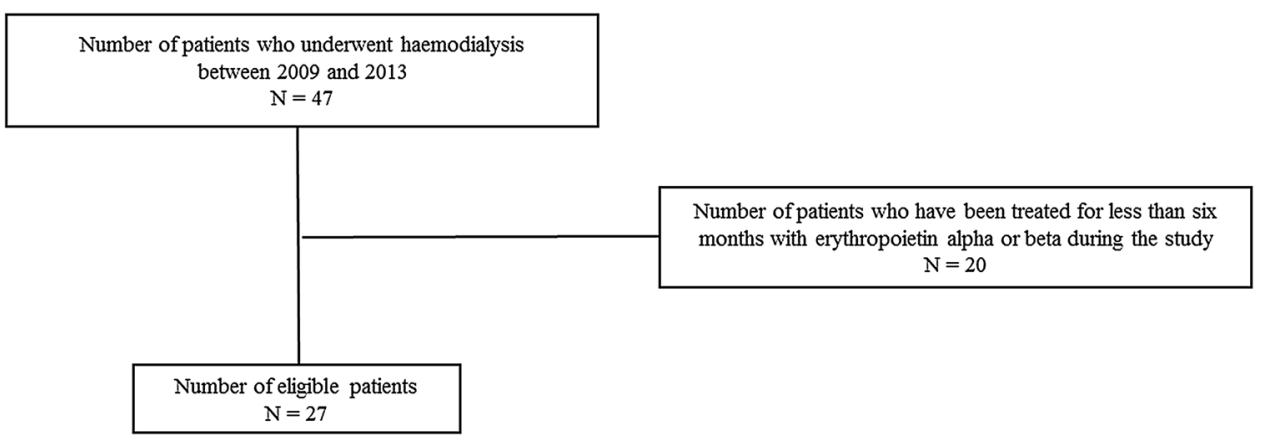

No patients were naïve to ESAs. All patients had been treated with erythropoietin alpha or beta for at least 6 months then with MPG-epoetin beta for at least 6 months. The average administered dose of erythropoietin alpha or beta was 7389 IU per week or 29,556 IU per month. The average administered dose of MPG-epoetin beta was $148 \mu \mathrm{g}$ per month (range 33-381).

The average blood haemoglobin level was $11.2 \pm 1.1 \mathrm{~g} /$ $\mathrm{dl}$ in the 'before' population and $11.0 \pm 1.2 \mathrm{~g} / \mathrm{dl}$ in the 'after' population. Moreover, the haemoglobin level for $96 \%$ of patients matched the target of $9-13 \mathrm{~g} / \mathrm{dl}$ recommended by the HAS, both in those following the 6-month treatment with erythropoietin alpha or beta and in those following the 6-month treatment with MPG-epoetin beta. Only one patient in the 'before' population did not reach $(8.9 \mathrm{~g} / \mathrm{dl})$ the haemoglobin target recommended by HAS. This did not influence the cost-minimisation analysis of this group or the robustness of the cost-minimisation analysis in this study.

Iron supplementation was performed according to good practice and adjusted to maintain adequate iron status (ferritin $>100 \mathrm{ng} / \mathrm{ml}$ and transferrin saturation [TSAT] $>20 \%$ ). The percentage of patients receiving supplementary iron at baseline was similar in each treatment group: MPG-epoetin beta $96 \%$ and erythropoietin alpha or beta $96 \%$.

Table 3 Direct medical costs according to the type of anaemia treatment
In total, 16 patients experienced one serious side effect and were hospitalised at least once in the course of the study. The most frequently observed serious side effects were influenza-like illness (five patients), deep vein thrombosis (two patients) and thrombosis at the fistula (two patients). Other less frequently observed serious side effects included sepsis, pulmonary oedema, respiratory distress, delirium and poorly controlled hypertension.

\subsection{Results of the Cost-Minimisation Analysis}

\subsubsection{Cost Measurement}

We considered only the direct medical costs related to the implementation of the two therapeutic strategies, which included all costs for hospital care (Table 3).

The cost-minimisation analysis showed that treating anaemia with MPG-epoetin beta in patients undergoing haemodialysis saved $€ 40,464$ per year ( $€ 133,166$ vs. 92,702; Wilcoxon $p=0.031$ ), corresponding to $€ 1499$ per patient per year. This represents savings of $€ 59,960$ per year for an active file of 40 patients (assuming a 100\% occupancy rate).

A univariate deterministic sensitivity analysis (tornado diagram; Figs. 3, 4) carried out on three relevant variables (Table 4) confirmed these results were robust.

\begin{tabular}{lll}
\hline Cost & $\begin{array}{l}\text { 'Before' group (6-month anaemia } \\
\text { treatment with erythropoietin } \\
\text { alpha or beta) }\end{array}$ & $\begin{array}{l}\text { 'After' group (6-month } \\
\text { anaemia treatment } \\
\text { with MPG-epoetin beta) }\end{array}$ \\
\hline Medical time for ESA prescription & $33.9 \mathrm{~h}$ & $17.4 \mathrm{~h}$ \\
Cost of medical time for ESA prescription & $€ 1424$ & $€ 731$ \\
Nursing care time for ESA administration & $39.4 \mathrm{~h}$ & $5.5 \mathrm{~h}$ \\
Nursing care for ESA administration & $€ 984$ & $€ 138$ \\
Acquiring ESAs & $€ 44,528$ & $€ 38,058$ \\
ESA administration (AMI) & $€ 13,054$ & $€ 1134$ \\
Acquiring injectable iron & $€ 4401$ & $€ 3978$ \\
Injectable iron administration (AMI) & $€ 2192$ & $€ 2312$ \\
Total & $€ 66,583$ & $€ 46,351$
\end{tabular}

AMI Acte Médico Infirmier (nursing procedure), ESA erythropoiesis-stimulating agent, MPG methoxy polyethylene glycol 
Fig. 3 Graphical representation of the univariate sensitivity analysis (tornado diagram) on the 'before' population

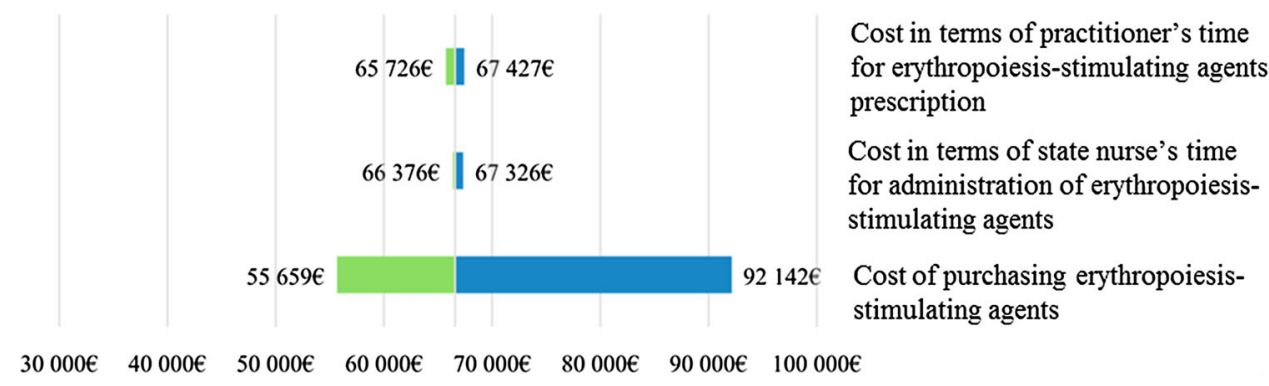

Cost in terms of practitioner's time prescription

Cost in terms of state nurse's time for administration of erythropoiesisstimulating agents

Cost of purchasing erythropoiesis$100000 €$
Fig. 4 Graphical representation of the univariate sensitivity analysis (tornado diagram) on the 'after' population
Table 4 Average value $(€)$ and confidence interval of the variables used for the sensitivity study

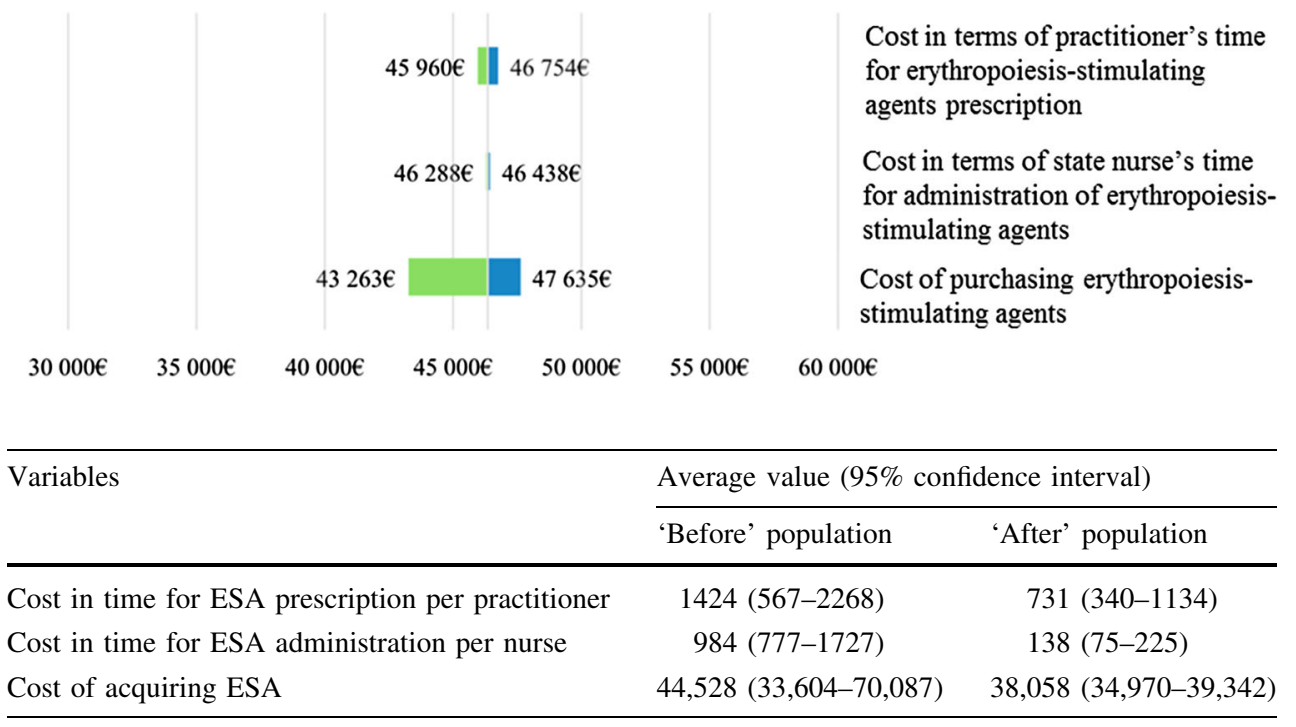

ESA erythropoiesis-stimulating agent
These sensitivity analyses showed that the cost of acquiring ESAs had the greatest impact on the overall cost. This is particularly pronounced in the 'before' population. The results showed that treating anaemia with MPG-epoetin beta saved $49 \%$ of practitioner time over 1 year, representing $33 \mathrm{~h}$ per year or $1.2 \mathrm{~h}$ per patient per year. It also saved 7 days of medical time per year for an active file of 40 patients per year. The results showed that treating anaemia with MPG-epoetin beta saved $87 \%$ of nurse time over 1 year, representing $68 \mathrm{~h}$ per year or $2.5 \mathrm{~h}$ per patient per year. It saved 15 days of nursing care time per year for an active file of 40 patients per year.

The results of this study therefore confirm the hypothesis that treating anaemia with MPG-epoetin beta in patients undergoing haemodialysis may reduce the costs related to the management of these patients in a hospital environment.

\section{Discussion}

This study demonstrated that administering ESAs once every 4 weeks instead of one to three times a week saved 7 days of medical time and 15 days of nursing care time per year.
This result confirms those of Schmid [9] and the Tempo [10] study. Schmid [9] showed that changing the treatment of anaemia to MPG-epoetin beta could save a significant amount of nursing care time, but the majority of included studies were retrospective.

This result also confirms those of a recent prospective study [15] that found MPG-epoetin beta to be more cost effective than erythropoietin beta (incremental cost-effectiveness ratio continuous erythropoietin receptor activator vs. epoetin beta at -\$US6457.5, year 2013 values), making it the dominant treatment for the management of anaemia in patients receiving chronic haemodialysis.

Another recent cost-utility analysis [16] suggested that managing anaemia with MPG-epoetin beta compared with epoetin beta in patients receiving dialysis may result in better outcomes with higher overall costs, but there were limitations.

It is important to mention that patients receiving dialysis have a higher risk of mortality due to cardiac complications. Indeed, anaemia increases the work output of the heart by favouring left ventricular hypertrophy and remodelling the big arteries. Therefore, administration of erythropoietin would limit cardiac complications. Furthermore, erythropoietin, a hormone with antioxidant and antiapoptosis effects, has a protective effect against ischemia 
reperfusion. This hormone also controls angiogenesis and increases endothelial cells in the process of tissue repair. However, erythropoietin can also cause high blood pressure. Thus, it is important that haemoglobin concentration is stable around its target value. This indicates ESAs with a long half-life [4] are of clinical interest.

Treating anaemia with long half-life ESAs requires fewer administrations, which in turn appears to limit the risk of mortality by reducing variations in haemoglobin levels. Indeed, variations in haemoglobin concentrations appear to increase the risk of mortality, likely because of the repeated episodes of tissue ischemia that negatively affect organs such as the heart.

The amount of time saved ( 15 days per year for an active file of 40 patients per year) would allow nurses to allocate time to improving the quality of their work, in turn enhancing the quality and overall safety of care.

The change in management strategies also showed cost benefits: treating anaemia with MPG-epoetin beta in patients undergoing haemodialysis would save $€ 59,960$ per year for the 40 patients currently undergoing haemodialysis in this hospital.

These results confirm some results in the literature. Ranchon et al. [7] showed that direct medical costs, particularly the costs of purchasing ESAs, account for the largest portion of direct medical costs. Our sensitivity analyses also showed that the cost of acquiring ESAs had the greatest impact on overall costs.

In our study, the administered dose of MPG-epoetin beta varied between 33 and $381 \mu \mathrm{g}$ per month, with an average administered dose of $148 \mu \mathrm{g}$ per month. Our results showed that changing anaemia treatment to MPG-epoetin beta reduced treatment costs.

This study has limitations. We examined direct medical costs but not side effects associated with ESA treatment. Furthermore, the small size of our sample means these results only show a trend, and it would be interesting to undertake another study in several centres to increase the cohort size. This would strengthen the observations suggested by this pilot study. It would also be interesting to include side effects associated with anaemia treatment and data on patient survival and quality of life.

In conclusion, treating anaemia with MPG-epoetin beta in patients undergoing haemodialysis may reduce costs related to the management of these patients in a hospital environment.

Acknowledgements The authors would like to acknowledge their colleagues, without whom this work could not have been carried out: Dr Valérie Daniel and Dr Frédéric Moal (pharmacist), Ms. Brigitte Marchand (management analysis), Dr Maud Cousin (doctor haemodialysis service), the nurses of the haemodialysis service, Dr Nathalie Andreu and Dominique Weil (doctor, Medical information and evaluation \& public health department - medical information unit), Prof. Patrick Saulnier (biostatistician), Mr Thibaut Brossard (deputy director in charge of management analysis), Mr Jean-Marie Chrétien (data manager), Dr Aurélie Jamet (clinical trials surveillance), the Centre for clinical research (Mr Henri Guépin, Ms AnneLise Gravouille, Ms Marie-Anne Poiron and the Dr Marc-Antoine Custaud), the members of the "Kidney network" (réseau REIN) Ms Assia Hami and the Prof. Maryvonne Hourmant, Ms Sandrine Bourguignon (health economist) and the staff of the Interregional Group for Clinical Research and Innovation (GIRCI Grand Ouest) committee for medical economic evaluation animation and support (Prof. Emmanuel Rush, Dr Solenne Brunet-Houdard and Dr ValéryPierre Riche).

Author contributions The paper was conceived by A.D., C.C. and V.B. A.D. contributed the study design, statistical analysis and writing of the manuscript. C.C. brought her expertise as a health economist to the evaluation of medical economic. V.B. brought her clinical expertise as a physician in haemodialysis. C.C. and V.B. commented on initial drafts of the manuscript and approved the final version.

\section{Compliance with Ethical Standards}

Funding No funding was received during the implementation of this study.

Conflict of interest Astrid Darsonval, Claire Cavalin and Virginie Besson have no conflicts of interest relevant to the content of this article.

Data availability statement The data that support the findings of this study are available from the corresponding author on request.

Open Access This article is distributed under the terms of the Creative Commons Attribution-NonCommercial 4.0 International License (http://creativecommons.org/licenses/by-nc/4.0/), which permits any noncommercial use, distribution, and reproduction in any medium, provided you give appropriate credit to the original author(s) and the source, provide a link to the Creative Commons license, and indicate if changes were made.

\section{References}

1. Agence de la biomedicine. REIN Annual report, 2013. French register of chronic renal failure replacement therapy. http://www. agence-biomedecine.fr/Le-programme-REIN. Accessed 8 April 2015.

2. Eckart KU. The CREATE trial-building the evidence. Nephrol Dial Transplant. 2001;16(Suppl 2):16-8.

3. Hsu C, Bates DW, Kuperman GJ, et al. Relationship between hematocrit and renal function in men and women. Kidney Int. 2001;59(2):725-31.

4. O'Riordan E, Foley RN. Effects of anemia on cardiovascular status. Nephrol Dial Transplant. 2000;15(Suppl 3):19-22.

5. Haute Autorité de Santé. HAS fact sheet for the appropriate use of the medicinal product. Anaemia in patients suffering from kidney failure: how to use erythropoiesis-stimulating agents. 2013. http://www.has-sante.fr/portail/jcms/c_1647165/fr/anemiechez-linsuffisant-renal-comment-utiliser-les-agents-stimulant-lery thropoiese-fiche-bum. Accessed 8 April 2015.

6. Haute Autorité de Santé. Guidance for improving the quality and safety of care: managing chronic patients undergoing haemodialysis. National results of the 2015 campaign. 2015. http://www.has-sante.fr/portail/jcms/c_970481/ipaqss-recueilsdes-indicateurs. Accessed 2 Feb 2016. 
7. Ranchon F, Hedoux S, Laville M, et al. Direct medical cost of erythropoiesis-stimulating agents in the treatment of anaemia in chronic kidney disease patients: literature review. Nephrol Ther. 2010;6(2):97-104.

8. Bernardo M, Crawford P, Hertel J, et al. Assessment of time and practice resources required to provide weekly or monthly erythropoiesis-stimulating protein therapy to chronic kidney disease patients in the physician office setting. J Manag Care Pharm. 2006;12(9):714-25.

9. Schmid H. Cost-effectiveness of continuous erythropoietin receptor activator in anemia. Clinicoecon Outcomes Res. 2014;6:319-30.

10. Allard B, Gregoire M, Ferrandini C, et al. tEmPo study: the benefits of monthly injections of erythropoietin. Pharm Hosp. 2011;46:13-22.

11. Sulowicz W, Locatelli F, Ryckelynck J-P, et al. Once-monthly subcutaneous C.E.R.A. maintains stable hemoglobin control in patients with chronic kidney disease on dialysis and converted directly from epoetin one to three times weekly. Clin J Am Soc Nephrol. 2007;2:637-46.

12. Levin N, Fishbane $S$, Valdes Canedo $F$, et al. Intravenous methoxy polyethylene glycol-epoetin beta for haemoglobin control in patients with chronic kidney disease who are on dialysis: a randomised non-inferiority trial (MAXIMA). Lancet. 2007;370:1415-21.

13. Opinion of the Transparency Commission (Commission de la Transparence)-19 December 2007-Mircera $50 \mathrm{mg} / 0,3 \mathrm{ml}$, $75 \mathrm{mg} / 0,3 \mathrm{ml}, 100 \mathrm{mg} / 0,3 \mathrm{ml}, 150 \mathrm{mg} / 0,3 \mathrm{ml}, 200 \mathrm{mg} / 0,3 \mathrm{ml}$, $250 \mathrm{mg} / 0,3 \mathrm{ml}$, solution injectable. http://www.has-sante.fr/portail/ upload/docs/application/pdf/ct-5111_mircera_.pdf. Accessed 17 Feb 2015

14. Collège des économistes de la santé (CES). Partial update of the methodology guide for the economic assessment of heath care strategies. Methodological recommendations. 2010. http://www. ces-asso.org/sites/default/files/upload/rapports/HAS-dec-2010. pdf. Accessed 17 Feb 2015.

15. Maoujoud O, Ahid S, Dkhissi H, et al. The cost-effectiveness of continuous erythropoiesis receptor activator once monthly versus epoetin thrice weekly for anaemia management in chronic haemodialysis patients. Anemia. 2015;2015:189404. doi:10.1155/ 2015/189404.

16. Maoujoud O, Ahid S, Cherrah Y. The cost-utility of treating anemia with continuous erythropoietin receptor activator or epoetin versus routine blood transfusions among chronic hemodialysis patients. Int $\mathrm{J}$ Nephrol Renovasc Dis. 2016;9:35-43. 